\title{
Sustainable Design of Innovation Chain of Strategic Emerging Industry Based on Ecological Chain Theory
}

\author{
Dong $\mathrm{Luo}^{1, *}$ \\ ${ }^{1}$ School of Economics and Management, Nanjing University of Aeronautics and Astronautics, Nanjing, Jiangsu 211106, \\ China
}

*Corresponding author. Email: 15083548621@163.com

\begin{abstract}
Aiming at the problem of industrial pollution caused by the existing model of SEI innovation chain, this paper uses the theory of natural ecological chain to optimize the sustainable design of innovation chain of SEI. Firstly, we compared the attributes of SEI innovation chain and natural ecological chain, and expounded the feasibility of applying ecological chain theory to the sustainable design of innovation chain in strategic emerging industries; and then, designed an ecological innovation chain model, which is divided into the core layer and auxiliary support layer, and discussed the flow relationship of innovation elements among internal subjects. The results show that by simulating the natural ecological chain, the innovation chain of strategic emerging industries can realize the circulation of innovation elements, improve the innovation efficiency, and reduce the damage to the environment, which is of great significance to the sustainable development of strategic emerging industries.
\end{abstract}

Keywords: SEI, innovation chain, ecological chain, sustainability

\section{INTRODUCTION}

SEI represents the direction of a new round of technological revolution and industrial transformation. They are the key areas to cultivate new driving forces for future development and obtain new competitive advantages. It plays an important leading and leading role in the overall and long-term development of economic and social development. They have created new impetus for the revitalization of global economic industry in the post-financial crisis era. From 2008 to 2017, the growth of China's socio-economic index has driven GDP growth by more than 1 percentage point every year, with a growth contribution rate of nearly $20 \%$. However, due to low technology maturity and imperfect innovation chain system, SEI not only promotes economic development, but also brings problems such as resource consumption and environmental pollution. Taking China as an example, the current SEI does not show the corresponding characteristics of high added value, low energy consumption and low pollution [1]. Compared with the traditional high-tech industry, high-tech industry also has serious pollution problems. With the increasingly serious pollution of "three wastes", the eco-industry and sustainable economic development have become the focus of attention in China and even the world [2]. How to coordinate high-knowledge and high-tech intensive industries with environmental resources and human health protection, and realize the "closed-loop" cycle of industrial technology from $\mathrm{R} \& \mathrm{D}$, transformation and waste treatment, has become an important topic of great concern in China and the world.

\section{THEORETICAL BASIS}

\subsection{Innovation chain}

The concept of the innovation chain originated from Schumpeter's theory of technological innovation. Schumpeter believes that innovation is not limited to R\&D innovation of technology itself. Innovation runs through the whole process of technology conception, technology research and development, technology generation, technology application and technology commercialization, and each independent link needs to be constructed with the help of certain elements [3]. In the process of innovation, enterprises should not only pay attention to commercialization, but also pay more attention to the research and invention of basic knowledge, so as to establish a reasonable relationship between each innovation link and make it a coherent and complete system [4].

SEI is usually a composite industry composed of industries with different functional structures. Through the close connection of the main body and link in the innovation chain, the innovation value-added and industrial 
development can be realized. According to the characteristics and connotation of SEI, the innovation chain of SEI is mainly composed of two stages: technology research and technology transformation. Technology R\&D stage reflects the process from technology input to technology output. Technology investment generally includes personnel investment and capital investment. Technological output represents technological achievements such as patents, while technological transformation is a process from technological output to economic output, generally characterized by sales revenue of new products.

It is worth noting that in the process of industrial technological transformation (product production), industrial pollutants are often produced, causing damage to the natural environment, which is a drawback of the current SEI innovation chain model. If the innovation chain can be extended forward, industrial pollutants will be used as resources, closed-loop flow into the SEI innovation chain for secondary use, reduce ecological damage and improve the efficiency of industrial innovation, which has important reference value and practical significance for promoting the ecological transformation of China's manufacturing industry, guiding the transformation and upgrading of China's manufacturing ecological innovation and sustainable development.

\subsection{Ecological chain in nature}

Natural ecological chain has the characteristics of closed-loop flow of material and energy. It is a food chain structure composed of different levels of species. One species feeds on another and gets the energy it needs. In this chain, the complex organic transfer of material and energy between the same species and different species, at the same time, the material and energy cycle in the ecological chain through some transformation, forming a material and energy cycle system with the food chain as the core, maintaining the dynamic balance of biological population [5].

According to the classification of natural species and the characteristics of predator-prey relationship, natural species are divided into producers, consumers and decomposers [6]. Producers mainly include higher green plants. They can convert solar energy, carbon dioxide and other substances into carbohydrates through photosynthesis, which is a process of transforming inorganic substances into organic substances. Consumers mainly include animals that feed on other species. Energy is mainly obtained by preying on other animals or plants. Decomposers mainly refer to some bacteria, fungi, protozoa, saprophytic plants, etc. they decompose the remains of animals and plants into simple compounds, which is the process of reducing organic matter to inorganic matter. Therefore, they are also called reducing agents. After that, inorganic matter flows into the natural ecological environment again for the producers to carry out photosynthesis and carry out a new round of material and energy cycle.

This mode of closed-circuit circulation of material and energy can be used for reference by SEI innovation chain. Therefore, this paper will use the idea of natural ecological chain for reference to design a sustainable SEI innovation chain, so that it can also realize the closed-loop cycle of innovation elements in the innovation chain, and realize the coordinated development of industry and industry, industry and ecological environment.

\subsection{Attribute comparison of ecological chain in nature and Innovation chain in SEI}

The innovation chain structure of SEI has similar characteristics with that of natural ecological chain. In the stage of R\&D. it involves many industry R\&D institutions, even universities, scientific research institutions, etc. they are mutually coupled, collaborative innovation, and ultimately produce technology. This population composed of multi-industry R\&D institutions is similar to the role of producers in the natural ecological chain. In the stage of technology transformation, most of the manufacturing industries in SEI draw on the relevant technologies developed by R\&D institutions. Through the exchange of materials and by-products, industries and enterprises carry out new product production, sales and other activities, and transform technology into economic benefits. This group of manufacturing industries is similar to that of consumers in the natural ecological chain Role. These are the two stages of most industrial innovation chain. Compared with the natural ecological chain, the innovation chain lacks the role of decomposer, which makes it difficult to form a closed loop of innovation chain.

The SEI include environmental protection service industry, which can recycle the waste products of other enterprises and end users, waste water, waste gas and other pollutants generated by production activities of other enterprises, and carry out corresponding treatment of the above pollutants through the use of environmental protection technology and green technology, so as to make the waste products and "three wastes" pollutants resource treated. After that, it flows to other enterprises and is reused. However, there is no reasonable planning and layout for this phenomenon, which makes some pollutants discharged into the nature, polluting soil, air, water and so on. If the environmental protection service industry can be integrated into the innovation chain system, an ecological innovation chain can be constructed to realize the closed-loop flow of materials, energy and pollutants, which is also very necessary. 
Table 1. Attribute comparison between innovation chain of SEI and ecological chain of nature

\begin{tabular}{|c|l|l|l|}
\hline $\begin{array}{c}\text { Main types of } \\
\text { ecological chain } \\
\text { of nature }\end{array}$ & \multicolumn{1}{|c|}{ Connotation } & $\begin{array}{c}\text { Main types of } \\
\text { innovation chain of } \\
\text { SEI }\end{array}$ & \multicolumn{1}{c|}{ Connotation } \\
\hline Producer & $\begin{array}{l}\text { The organism that can produce } \\
\text { organic matter by photosynthesis in } \\
\text { nature }\end{array}$ & $\begin{array}{l}\text { Main body of } \\
\text { innovative R\&D }\end{array}$ & $\begin{array}{l}\text { High-tech enterprises, R\&D } \\
\text { institutions, universities, etc., } \\
\text { responsible for technology R\&D }\end{array}$ \\
\hline Consumer & $\begin{array}{l}\text { Energy can only be obtained by } \\
\text { feeding on other green plants or } \\
\text { animals to synthesize organic matter }\end{array}$ & $\begin{array}{l}\text { Main body of } \\
\text { technology } \\
\text { application }\end{array}$ & $\begin{array}{l}\text { Manufacturing enterprises, } \\
\text { responsible for the production and } \\
\text { processing of products }\end{array}$ \\
\hline Decomposer & $\begin{array}{l}\text { Microorganisms that decompose the } \\
\text { remains of dead plants and animals in } \\
\text { the ecosystem }\end{array}$ & $\begin{array}{l}\text { Main body of } \\
\text { environmental } \\
\text { protection service }\end{array}$ & $\begin{array}{l}\text { Environmental protection } \\
\text { enterprises, responsible for waste } \\
\text { recycling, resource treatment, etc. }\end{array}$ \\
\hline
\end{tabular}

From the above analysis, we can see that the innovation chain of SEI involves the coupling relationship of interdependence, competition and cooperation among industry entities. In essence, it can be regarded as an innovation ecosystem of SEI, which is similar to the ecological chain in nature. The organisms in the natural ecological chain can be divided into producers, consumers and decomposers according to their functions. The analogy analysis of SEI innovation chain is shown in Table 1.

\section{DESIGN OF ECOLOGICAL INNOVATION CHAIN MODEL FOR SEI}

The above analysis shows that there are similarities between the innovation chain of SEI and the natural ecological chain in terms of internal structure and internal mechanism, which has theoretical basis and conforms to the actual situation. The material and energy flow in the innovation chain of SEI generally refers to the flow of technology, knowledge and information. The purpose of incorporating ecological thinking into the research framework is to simulate the closed-loop mode of material and energy in the natural ecological chain and realize the closed-loop flow of technology, knowledge and information in the innovation chain of SEI.

Therefore, taking the natural ecological chain as the basic structure and according to the development characteristics of SEI in reality, a multi-level strategic emerging ecological innovation chain is designed, which is composed of core layer and support layer. Its conceptual model is shown in Fig. 1.

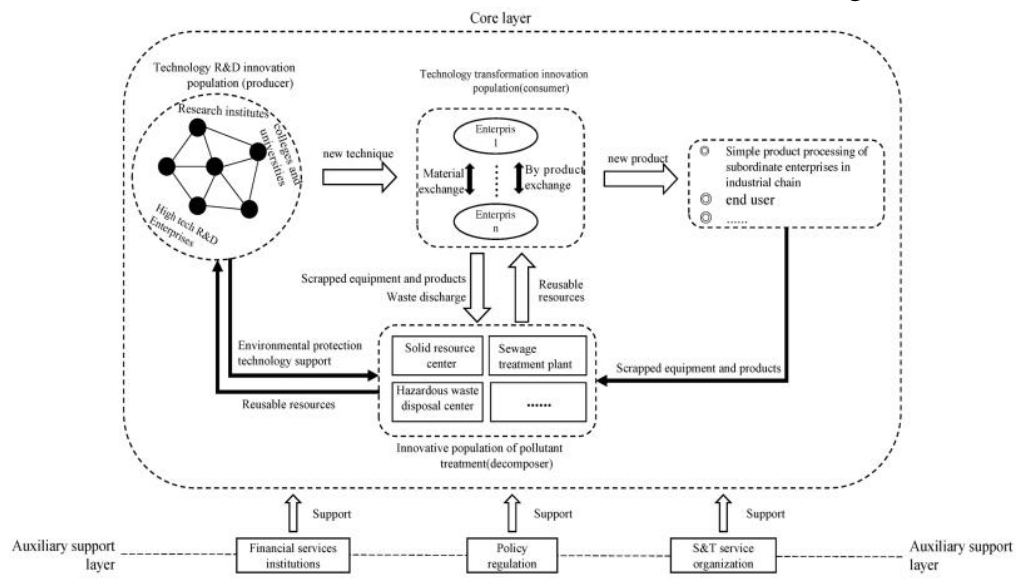

Figure 1. conceptual model of ecological innovation chain of SEI

\subsection{Core layer}

The coupling relationship of different sectors in the innovation chain constitutes the core layer of ecological innovation chain of SEI. The core layer of innovation chain is shown in Fig. 1.

Technology R\&D innovation cluster is equivalent to producer, technology transformation innovation cluster is 
equivalent to consumer, and pollution control innovation cluster is equivalent to decomposer. Technological $R \& D$ innovation cluster mainly transfers the technological achievements of R\&D to technological transformation innovation cluster for production and manufacturing, and environmental protection treatment technology to pollutant treatment innovation cluster for pollutant treatment; technology transformation innovation cluster applies the technology generated by technology R\&D innovation cluster to product production of manufacturing enterprises With the deepening of professional division of labor, R\&D innovation cluster is often divided into multiple levels to process the products layer by layer, and finally realize the value-added of products. In the process of technological research and development or production, innovative production activities often result in the discharge of wastewater, waste gas and solid waste to varying degrees, and the scrapping of $\mathrm{R} \& \mathrm{D}$ and production equipment or products beyond their service life. These pollutants which will cause deterioration of the ecological environment will be treated intensively and flow into the pollutant treatment innovation cluster. The innovative cluster, supported by environmental protection technology, through a series of treatment, the pollutants are returned to the technological research and development innovation cluster and technology transformation innovation cluster again as available resources, so as to realize the "decomposition" and reutilization of pollutants. This mode can greatly improve the economic and ecological benefits of SEI, and it is an effective way for SEI to develop from ecological industries.

\subsection{Auxiliary support layer}

The government, financial institutions and science and technology intermediary service institutions are the main supporting bodies of the industrial innovation chain. In general, they do not directly engage in production activities, but serve as auxiliary systems for the sustainable development of technology research and development and product production in the core layer of the industrial innovation chain, and provide superior environment (resources and infrastructure), system guarantee and behavior standard support for the development of the main body at the production factor level. The macro support is shown in Fig. 1. Among them, the government relies on policy support and rules and regulations to create a "hard environment" for industrial development. At the same time, it also standardizes the behavior of enterprises to ensure a fair and free cluster "soft environment"; financial service institutions provide capital services and capital regulation; and science and technology intermediary services provide professional consulting services related to technology research and development. The cooperative operation mode between the auxiliary support layer and the core layer will directly affect the flow effect of information and material resources in the core layer of innovation chain.

\section{CONCLUSION}

Aiming at the problems of industrial pollution in the process of innovation and development of SEI, this paper designs a sustainable model of innovation chain of SEI which can realize closed-loop flow of innovation elements by using the idea of natural ecological chain for reference. Firstly, the elements and attributes of SEI innovation chain and natural ecological chain are analyzed by analogy, and the similarities and differences between them are found. Secondly, according to the types of species producers, consumers and decomposers in the natural ecological chain, and the relationship between them, the ecological innovation chain model of SEI is designed. It is divided into core layer and auxiliary support layer, and its internal structure is analyzed, and the flow characteristics of innovation elements among them are analyzed. These innovative subjects and elements work together to promote the ecological innovation chain of SEI to a sustainable and stable state.

\section{REFERENCES}

[1] Wang Ting, Wang Haitian. Research on the Evolution of the Coupling Relationship between High-Tech Industry Agglomeration Degree and Ecological Environment [J]. Science and technology progress and countermeasures, 2020,37 (15): 44-53. (In Chinese)

[2] Hou Jian, Chen Heng. Research on green transformation performance and driving factors of technological innovation in China's high patent intensive manufacturing industry [J]. Management review, 2018 (4): 59-69. (In Chinese)

[3] Schumpeter. Economic development theory [M]. China Social Science Press, 2009. (In Chinese)

[4] Debra M.Amidon. Innovation Strategies for the Knowledge Economy: The Ken Awakening explain the principles of knowledge innovation [EB/OL]. www.entovation.com, 1993-08-23.

[5] Sun X Q. Research on network innovation of wood based panel industry cluster in Shandong Province Based on ecological chain [D]. 2016. (In Chinese)

[6] Li Wanqiu, Dong Jie, LV Weiwei. Analysis on economic structure and operation mechanism of forestry ecological industry chain $[\mathrm{J}]$. Times economic and trade, 2017 (03): 76-81. (In Chinese) 